\title{
Quality of primary care physicians' communication of diabetes self-management during medical encounters with persons with diabetes mellitus in a resource-poor country
}

\author{
OS Ojo ${ }^{a *}$ (D) SO Malomo ${ }^{a}$, AO Egunjobi ${ }^{b}$ (D) AOA Jimoh ${ }^{a}$ and MO Olowere ${ }^{a}$ \\ ${ }^{a}$ Family Medicine Department, Federal Medical Centre, Abeokuta, Nigeria \\ ${ }^{b}$ Family Medicine Department, Sacred Heart Hospital, Abeokuta, Nigeria \\ *Corresponding author, email: ojo_teenager@yahoo.com
}

Background: Most of the Nigerian studies on the determinants of diabetes self-management have focused on patient-related factors. There is no previous local study that examined the quality of diabetes self-management education provided by primary care physicians to people with diabetes mellitus.

Methods: A descriptive cross-sectional study was conducted among 105 primary care physicians during a workshop. The quality of diabetes self-management education provided by the physicians was assessed using a self-designed scale of 39 Likert questions derived from American Association of Diabetes Educators seven domains of diabetes self-management. Cronbach's reliability coefficient of each domain/subscale was $\geq 0.7$. The data was analysed using the independent sample $t$-test and one-way ANOVA.

Results: Over half of the physicians provided 'inadequate quality' diabetes self-management education in all the domains. Physicians had the highest mean score in the 'taking medication' domain $(4.35 \pm 0.59)$. The mean scores in the 'problemsolving domain' $(3.63 \pm 0.74)$ and the 'being active domain' $(3.57 \pm 0.71)$ were low. The quality of diabetes self-management education provided by the physicians was not associated with any of the physician characteristics.

Conclusion: The quality of physicians' communication of diabetes self-management was suboptimal in this study. The majority of the adequately communicated diabetes self-management behaviours were risk factors reduction related and disease-centred. Thus, training of primary care physicians on diabetes self-management education is recommended because of the key role these physicians play in diabetes management in resource-poor countries.

Keywords: diabetes self-management, patient-physician communication, primary care physicians, resource-poor countries, Nigeria

\section{Introduction}

Globally, the number of people with diabetes mellitus (DM) is rising at an alarming rate and is expected to exceed 629 million by $2045 .{ }^{1}$ According to the International Diabetes Federation (IDF), one in every 20 Nigerians currently has DM. ${ }^{1}$ The increasing prevalence of DM and the increasing focus on the reduction of morbidity and mortality associated with DM prevalence make the education of persons with DM on effective disease management vital.

Diabetes education continues to be cited as a foundation for effective diabetes care and supports the philosophy of chronic care models. ${ }^{2,3}$ Central to diabetes education is the provision of information on diabetes self-management to persons with DM. Diabetes self-management education (DSME) is a collaborative process through which people with or at risk of diabetes gain the knowledge and skills needed to modify their behaviours and successfully self-manage the disease and its related conditions. $^{4}$

DSME can be provided by healthcare professionals from various disciplines with varying levels of expertise in diabetes education and management. The question of who provides self-management education to persons with DM depends on the available expertise in any practice region. While the education of people with DM is universally recognised to be within the purview of diabetes educators, primary care physicians who see the majority of people with diabetes mellitus often assume the role of diabetes educators in Nigeria and other resource-poor countries where there are fewer certified diabetes educators., Thus, it is imperative for primary care physicians in developing countries like Nigeria to know how to effectively communicate diabetes self-management to persons with DM at every contact.

A large body of evidence supports the effectiveness of DSME in improving diabetes outcomes. ${ }^{7-10}$ A meta-analysis showed that patients who received DSME in a group setting had improved diabetes knowledge and reduced fasting blood glucose levels, glycosylated haemoglobin (HbA1c) levels, systolic blood pressure levels, and body weight. ${ }^{9}$ Similarly, a previous study had reported findings that strongly support cost reduction as a benefit of DSME. ${ }^{10}$

Despite the obvious benefits of DSME, self-management among people living with DM is still very poor in Nigeria. ${ }^{7,8}$ Studies on the factors influencing the practices of self-management among people with DM in Nigeria have centred on patient variables such as socioeconomic status, culture and religious beliefs. $^{7,8}$ There has been no previous Nigerian study that assessed the partnership between people living with DM and physicians, and none examined the quality of DSME provided to patients with DM by the Nigerian physicians. In developed countries where the quality of diabetes self-management communication during medical encounters has been explored, the 
focus has been on patients' ratings of the effectiveness of providers' communication of diabetes self-management. ${ }^{11,12}$ An assessment of the quality of diabetes self-management information communicated to patients with DM from providers may be more objective.

The majority of patients in Nigeria, including persons living with DM, trust the attending physicians to make decisions, set objectives and provide directives on what to do while they make an effort to adhere to the directives. ${ }^{13,14}$ Many healthcare settings in Africa do not have structured diabetes self-management programmes, ${ }^{6,7}$ and the only opportunity to provide DSME comes up when people with DM are in their primary care physicians' office. Thus, the idea of blaming the cause of poor self-management practice among people with DM on patient-related variables, as seen in several Nigerian studies, ${ }^{6-8}$ may be unfair because people can only make an informed and healthy decision regarding their DM management when they are empowered through education. In view of this, the researchers were motivated to assess the quality of DSME provided by primary care physicians during medical encounters with persons with DM in a resource-poor country where physicians double as the diabetes educators. This may assist in designing a resource guide to a diabetes self-management education protocol for primary care physicians and development of patient self-management tools.

\section{Materials and methods}

\section{Study site}

This study was conducted at Ace Medicare Clinics Limited, Ota, Ogun State during the two-day update course on sexual health issues in primary care that was organised by the Faculty of Family Medicine of the National Postgraduate Medical College of Nigeria (NPGMCN) between March 8 and 9, 2018. Ota is a town located in South West Nigeria. The hospital is currently accredited by the Faculty of Family Medicine of the National Postgraduate Medical College of Nigeria to train Family Medicine Senior Residents. It is also an accredited continuing professional development (CPD) provider. It organises bi-annual lectures on topical issues for doctors.

\section{Study population}

This comprised primary care physicians at different levels of professional qualification in the speciality of family medicine. This included diplomates in family medicine, family medicine residents, and consultants/fellows in family medicine. A total of 302 physicians attended the workshop.

\section{Study design}

This was a descriptive cross-sectional study. The study was primarily carried out with a quantitative approach using a selfadministered questionnaire.

\section{Instrument}

Data were collected from the respondents with the aid of a selfadministered structured questionnaire designed by the authors. The information obtained included the respondents' demographic characteristics and the quality of DSME they gave to people with DM. The demographic characteristics included age, gender, professional qualification, length of practice, DSME programme in respondents' practice setting, awareness of diabetes self-management and formal training in DSME.
The quality of respondents' communication of diabetes selfmanagement was assessed with the use of a self-designed scale that was developed from the American Association of Diabetes Educators 7 domains (AADE7) of self-care behaviours essential for effective diabetes-self-management. ${ }^{4}$ AADE7 has been defined to guide the process of DSME and help persons with DM achieve behaviour change. ${ }^{15}$ The seven self-care behaviours essential for successful and effective diabetes self-management are healthy eating, being active, taking medications, monitoring, problem-solving, reducing risks and healthy coping.

The content under the seven domains of self-care behaviour in AADE7 was used to develop a 51-item Likert-type questionnaire. These Likert items were categorised into Likert subscales grouped under the seven domains. Responses to each question were never, rarely, sometimes, often, always. The responses were scored never (1), rarely (2), sometimes (3), often (4), always (5). The content validity of the scale was assessed by two diabetes experts (a family physician with a special interest in DM and an endocrinologist). The scale was reduced to 44 items after their review. Prior to the use of the questionnaire, the reliability of the scale was assessed through a pilot test among 25 primary care physicians (resident doctors and consultants) working in a tertiary hospital. The items under each subscale were subjected to a reliability analysis using Cronbach's alpha. An alpha equal to or greater than 0.70 was defined as adequate internal consistency. Based on the result, the items under each subscale underwent review and modifications to ensure that they measured a single unidimensional latent construct. The final form was a 39 Likert-type questions under seven subscales: healthy eating (5 Likert items); being active (7 Likert items), taking medications (6 Likert items), monitoring (5 Likert items), problem solving (6 Likert items), reducing risks (6 Likert items) and healthy coping (4 Likert items).

\section{Data collection}

Prior to commencement of the study, ethical clearance was obtained from the Ethical Committee of the Ace Medicare Clinics Ota and the NPGMCN (Faculty of Family Medicine). A total number of 120 respondents comprising fellows, residents and diplomates in family medicine were selected by simple random sampling out of the 302 that attended the workshop. The questionnaire was administered to them and they completed it without any consultation among themselves in 10 minutes.

\section{Data analysis}

Data were analysed using the Statistical Package for the Social Sciences $^{\mathrm{TM}}$ (IBM Corp, Armonk, NY, USA) version 22.0. The frequency distribution of the data was analysed to determine normality. Cronbach's reliability of the scale used was further assessed. Data were presented using appropriate tables. Descriptive analyses such as frequency and mean were obtained to summarise the data. The respondents' item mean score, summated domain mean score and summated total mean score were calculated. The independent samples t-test was used to compare means of dichotomous categorical independent variables. As an extension of a t-test for independent samples, one-way ANOVA was used when there were two or more independent groups. The level of significance was set at $p \leq 0.05$.

\section{Results}

Of the 120 twenty questionnaires distributed, 15 questionnaires had missing data giving a completion rate of $87.5 \%$. The mean 
Table 1: General characteristics of respondents

\begin{tabular}{|c|c|c|}
\hline Variable & Category & $\begin{array}{l}\text { Frequency (\%) } \\
\text { or mean } \pm S D\end{array}$ \\
\hline Age & $27-61$ & $37 \pm 5.93$ \\
\hline \multirow[t]{2}{*}{ Gender } & Male & $56(53.3)$ \\
\hline & Female & $49(46.7)$ \\
\hline \multirow[t]{4}{*}{ Professional status } & $\begin{array}{l}\text { Medical } \\
\text { officers }\end{array}$ & $1(1.0)$ \\
\hline & Residents & $71(67.6)$ \\
\hline & $\begin{array}{l}\text { Senior } \\
\text { residents }\end{array}$ & $29(27.6)$ \\
\hline & Consultants & $4(3.8)$ \\
\hline \multirow[t]{2}{*}{ Type of practice } & Private & $16(15.2)$ \\
\hline & Public & $89(84.8)$ \\
\hline Length of practice & $2-35$ & $9.97 \pm 5.19$ \\
\hline \multirow[t]{4}{*}{ Length of practice categorised } & $\begin{array}{l}\text { Less than } 5 \\
\text { years }\end{array}$ & $8(7.6)$ \\
\hline & $5-10$ years & $63(60.0)$ \\
\hline & $11-15$ years & $23(21.9)$ \\
\hline & $\geq 16$ years & $11(10.5)$ \\
\hline \multirow{2}{*}{$\begin{array}{l}\text { Awareness of diabetes } \\
\text { self-management }\end{array}$} & Yes & $105(100.0)$ \\
\hline & No & $0(0.0)$ \\
\hline \multirow{2}{*}{$\begin{array}{l}\text { Formal training on diabetes self- } \\
\text { management }\end{array}$} & Yes & $42(40.0)$ \\
\hline & No & $63(60.0)$ \\
\hline \multirow{2}{*}{$\begin{array}{l}\text { Group counselling programme } \\
\text { for persons with DM in } \\
\text { respondents' practice setting }\end{array}$} & Yes & $55(52.4)$ \\
\hline & No & $50(47.6)$ \\
\hline \multirow[t]{6}{*}{$\begin{array}{l}\text { Place of practice according to } \\
\text { geo-political zones in Nigeria }\end{array}$} & $\begin{array}{l}\text { North- } \\
\text { central }\end{array}$ & $16(15.2)$ \\
\hline & North-east & $2(1.9)$ \\
\hline & North-west & $2(1.9)$ \\
\hline & South-east & $14(13.3)$ \\
\hline & South-south & $18(17.1)$ \\
\hline & South-west & $53(50.6)$ \\
\hline
\end{tabular}

age was $37.00 \pm 5.93$ years. The majority of the respondents $(92.40 \%)$ had practised for more than five years (Table 1$)$.

The frequency histogram of the data showed that the data were normally distributed. The subscales/domains had good internal consistency (Cronbach's alpha $\geq 0.70$ ), indicating that items under each subscale/domain were measuring a unitary construct (Table 2). The mean scores of respondents in all the domains were first made in order to obtain a model for presenting the results of quality of respondents' communication of diabetes self-management to persons with $\mathrm{DM}$. The mean scores of respondents in each domain were divided into two categories using the mean score that corresponded to the 50th percentile as the cut-off point for each domain. The quality of respondents' communication of self-management behaviours to people with diabetes mellitus was categorised as 'inadequate' if the respondent's mean score was less than the 50th percentile of the domain's mean score and 'adequate' if it was more than or equal to the 50th percentile of the domain's mean score. The cut-off mean scores for the domains, the mean score interval for adequate and inadequate quality of self-management communication for the domains and the percentages of participants under adequate and inadequate quality for each domain of selfmanagement behaviours are given in Table 2. Over half of the participants fell within the 'inadequate' category of the selfdeveloped mean scores cut-off points in all the seven domains (see Table 2).

Of the 39 items, the mean scores of 19 items asterisked in Table 3 fell within the 'inadequate' category of the self-developed cut-off points for each domain. The 'taking medication' domain had the highest mean score $(4.35 \pm 0.59)$. The 'problem solving' and 'being active' domains had low mean scores of $3.63 \pm 0.74$ and $3.57 \pm 0.71$ respectively. The behavioural item 'Check blood glucose before and after exercise' had the lowest item mean score $(2.74 \pm 1.20)$ (see Table 3 ).

The independent sample t-test revealed that there was no association between the quality of respondents' communication of diabetes self-management behaviours and gender based on the summated total mean score of the respondents $(t=0.90$; $p=0.37)$. However, male respondents had a higher mean score than their female counterparts in the problem-solving domain $(\mathrm{t}=2.59 ; p=0.01)$ based on domain mean score analysis. (Table 4)

There was no association between the quality of respondents' communication of diabetes self-management behaviours and formal training in diabetes self-management based on summated total mean score analysis using independent sample ttest $(\mathrm{t}=1.71 ; p=0.09)$. However, based on the specific domain

Table 2: Summary descriptions of the scale used for data collection and the self-developed cut-off points for the model

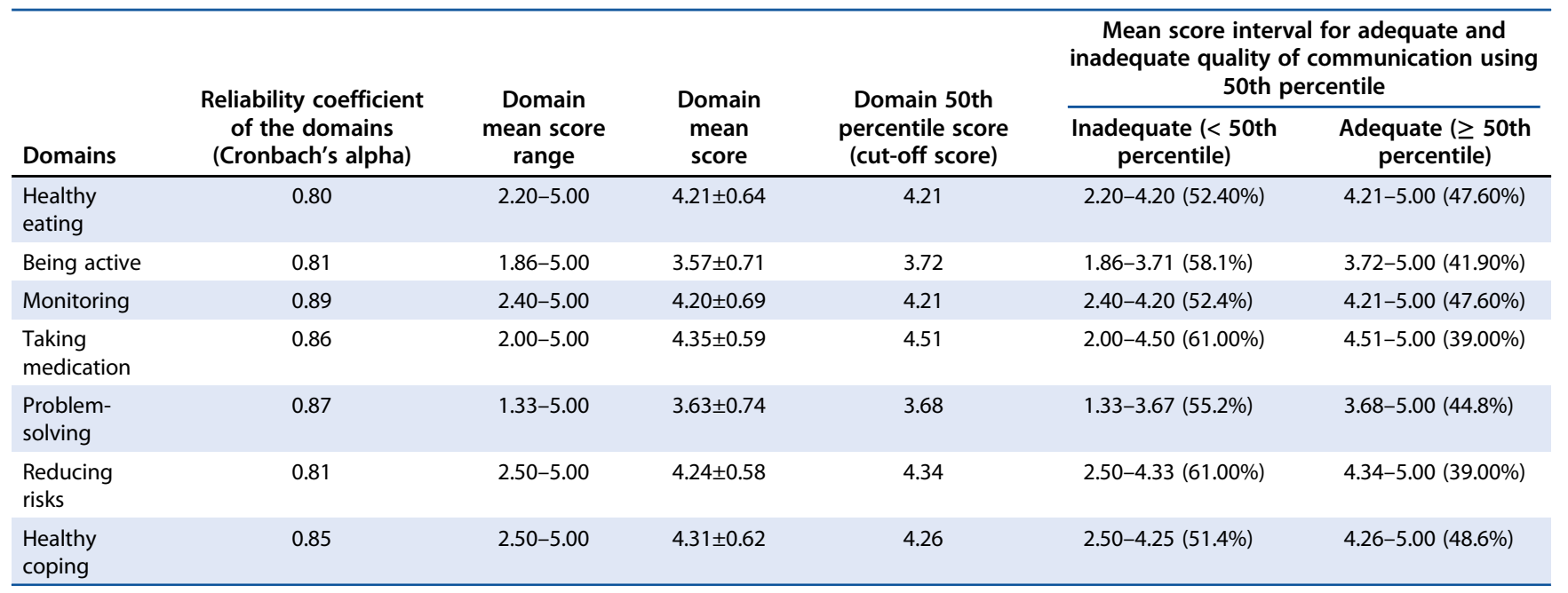


Table 3: Item mean and domain mean of the respondents

\begin{tabular}{|c|c|c|c|}
\hline AADE domains & Behavioural items & Item (mean \pm SD) & Domain mean $\pm S D$ \\
\hline \multirow[t]{4}{*}{ Healthy eating } & The foods that are best to eat or avoid & $4.54 \pm 0.67$ & $4.21 \pm 0.64$ \\
\hline & When and how much to eat & $4.33 \pm 0.84$ & \\
\hline & Preventing high or low blood sugar & $4.49 \pm 0.67$ & \\
\hline & Setting goals for healthy eating ${ }^{a}$ & $3.98 \pm 0.97$ & \\
\hline \multirow[t]{7}{*}{ Being active } & Importance of exercise in DM management & $4.60 \pm 0.57$ & $3.57 \pm 0.71$ \\
\hline & Daily exercise for 30 minutes at least 5 times a week & $4.18 \pm 0.84$ & \\
\hline & Don't overdo the exercise ${ }^{a}$ & $3.69 \pm 1.09$ & \\
\hline & Check blood glucose before and after exercise ${ }^{a}$ & $2.74 \pm 1.20$ & \\
\hline & Keep track of your activity ${ }^{a}$ & $3.43 \pm 1.15$ & \\
\hline & Join a gym and/or league and engage in a sport ${ }^{\mathrm{a}}$ & $3.19 \pm 1.16$ & \\
\hline & Mix the exercise-try a few different things ${ }^{a}$ & $3.16 \pm 1.13$ & \\
\hline \multirow{4}{*}{ Monitoring } & When to check blood glucose and what the values mean & $4.24 \pm 0.75$ & \\
\hline & How to record blood glucose results & $4.35 \pm 0.78$ & \\
\hline & What to do when the values are not normal ${ }^{\mathrm{a}}$ & $4.13 \pm 0.89$ & \\
\hline & Regular blood pressure, cholesterol and weight check ${ }^{a}$ & $4.16 \pm 0.88$ & \\
\hline \multirow[t]{6}{*}{ Taking medication } & Knowing their medications & $4.72 \pm 0.55$ & $4.35 \pm 0.59$ \\
\hline & The reason for using the medications & $4.78 \pm 0.50$ & \\
\hline & How the medications are used & $4.50 \pm 0.65$ & \\
\hline & Knowing some of the side effects of the medications ${ }^{a}$ & $4.02 \pm 0.85$ & \\
\hline & Knowing what to do in the event of side effects ${ }^{a}$ & $4.25 \pm 0.91$ & \\
\hline & Knowing what to do if the medications are forgotten ${ }^{a}$ & $3.81 \pm 1.01$ & \\
\hline \multirow[t]{5}{*}{ Problem-solving } & Problems may arise even when they follow self-management of DM & $3.69 \pm 0.84$ & $3.63 \pm 0.74$ \\
\hline & Don't beat themselves up when problem occurs & $3.69 \pm 0.86$ & \\
\hline & Think about what was different when problems arise ${ }^{a}$ & $3.49 \pm 1.01$ & \\
\hline & Discuss possible solutions with your doctor & $3.92 \pm 0.99$ & \\
\hline & Try the new solution and evaluate if it is working ${ }^{a}$ & $3.55 \pm 1.04$ & \\
\hline \multirow[t]{6}{*}{ Reducing risk } & Don't smoke & $4.66 \pm 0.65$ & $4.24 \pm 0.58$ \\
\hline & See your doctor regularly & $4.76 \pm 0.49$ & \\
\hline & Visit the eye doctor at least once a year ${ }^{\mathrm{a}}$ & $3.90 \pm 0.98$ & \\
\hline & The need for regular dental check-up ${ }^{a}$ & $3.15 \pm 1.11$ & \\
\hline & Take care of your feet & $4.49 \pm 0.77$ & \\
\hline & Report any abnormal feelings to the doctor & $4.50 \pm 0.71$ & \\
\hline \multirow[t]{4}{*}{ Coping } & Seeking support from family and friends ${ }^{a}$ & $4.11 \pm 0.81$ & $4.31 \pm 0.62$ \\
\hline & Being active & $4.50 \pm 0.62$ & \\
\hline & Thinking positive & $4.34 \pm 0.74$ & \\
\hline & Being good to yourself & $4.29 \pm 0.78$ & \\
\hline
\end{tabular}

asterisks indicate items with mean scores that fall in the 'inadequate' category based on the domain's cut-off.

mean score, the mean score of participants who had formal training in self-management of diabetes was higher than those who did not have formal training in the healthy eating domain $(\mathrm{t}=2.31, p=0.02$ ) (Table 4$)$.

There was no association between the quality of respondents' communication of diabetes self-management and availability of group counselling programmes on diabetes self-management in respondents' practice setting based on specific domain mean score analysis and summated total mean score analysis (see Table 4).

The results of a one-way ANOVA test demonstrated that there was no association between the quality of respondents' communication of diabetes self-management and age group, length of practice and professional status based on specific domain mean score and summated total mean score (Table 5).

\section{Discussion}

The quality of physicians' communication of diabetes self-management in this study is sub-optimal. More than half of the primary care physicians' communications of the seven domains of diabetes self-management were of inadequate quality. Similarly, the communication of 19 of the 39 questions (asterisked in Table 4) were also of inadequate quality based on the selfdeveloped cut-off points for each domain. Unlike developing countries where there is a paucity of study on the quality of physicians' communication of diabetes self-management, numerous studies on this theme have been conducted in developed countries. ${ }^{11,12,16-18}$ Although these studies focus on patients' 
ratings of providers' communication of diabetes self-management, the general consensus from these studies was also poor communication of diabetes self-management. ${ }^{16-18}$

The poor quality of diabetes self-management communication might explain the rising trend of poor self-management behaviour and consequent poor glycaemic control reported in different studies. ${ }^{6-8}$ The quality of communication between healthcare professionals and people with DM has been cited as the most critical indicator of successful DSME. ${ }^{19}$ In Nigeria, the number of diabetes educators who should be providing DSME to persons with DM is limited. ${ }^{6,7}$ Hence, the care of persons with DM who are seen by primary care physicians is often without the involvement of certified diabetes educators. This underscores the fact that primary care physicians working in developing countries with few diabetes educators have to take up this role. They must use every contact with persons with DM as a means of training them on all matters associated with diabetes self-management. Hence, training of primary care physicians to provide therapeutic problem-solving, counselling and regimen adjustments for persons with DM should be incorporated in their professional development.

The group of questions that were adequately communicated by the primary care physicians in this study were basically traditional education on risk reduction while the questions that were inadequately communicated (asterisked questions) were related to goal setting and problem-solving skills. This finding is not surprising; previous studies have also shown that primary care physicians provide more risk-reduction based education to persons with DM and less information on problemsolving skills. ${ }^{17,18,20}$ Shah et al. reported that primary care physicians may only provide information on risk reduction such as weight-reduction counselling, exercise counselling and diet/ nutrition counselling to patients without giving education on goal settings and the skills training they need to manage their DM effectively. ${ }^{20}$

The deficiency of the primary care physicians in communicating the aspects of diabetes self-management that involve goal setting and problem-solving in this study is further reinforced by the lowest mean scores reported in the being active and problem-solving domains. Among all the domains, these domains entail a great deal of goal setting and problemsolving. DSME is more than traditional patient education on risk reduction; it also involves helping patients to set achievable goals and learn techniques of problem-solving that will improve their health outcome.

Traditional patient education on risk reduction is diseasespecific, while working with patients to provide knowledge about their condition as well as training them on goal setting and problem-solving skills are patient-centred. ${ }^{21}$ The ideal chronic disease self-management encompasses the provision of disease-specific information, goal setting and problem-solving skills. This ensures that patients embrace the behavioural changes needed to improve self-efficacy and health outcomes. ${ }^{21}$ There is a need for a paradigm shift from the current disease-centred communication to patientcentred communication. This will enhance patients' understanding of their illnesses and improve their self-confidence to take decisions on their health. It is imperative to emphasise behaviours related to goal setting and problem-solving when designing a diabetes self-management training programme for primary care physicians. 
Table 5: Association between quality of respondents' communication of diabetes self-management and age group, length of practice and professional status

\begin{tabular}{|c|c|c|c|c|c|}
\hline \multirow[b]{2}{*}{ Variable } & \multirow[b]{2}{*}{ Category } & \multirow[b]{2}{*}{ Frequency } & \multicolumn{3}{|c|}{ Summated total mean score } \\
\hline & & & Mean \pm SD & $F$ & Sig. (2-tailed) \\
\hline \multirow[t]{3}{*}{ Age group } & Young & 75 & $4.08 \pm 0.54$ & 0.45 & 0.72 \\
\hline & Middle aged & 29 & $4.06 \pm 0.49$ & & \\
\hline & Elderly & 1 & 4.00 & & \\
\hline \multirow[t]{4}{*}{ Length of practice } & $<5$ years & 8 & $4.00 \pm 0.63$ & 0.03 & 0.97 \\
\hline & $5-10$ years & 63 & $4.11 \pm 0.54$ & & \\
\hline & $11-15$ years & 23 & $3.98 \pm 0.50$ & & \\
\hline & $\geq 16$ years & 11 & $4.15 \pm 0.34$ & & \\
\hline \multirow[t]{4}{*}{ Professional status } & Medical officer & 1 & 4.00 & 0.34 & 0.79 \\
\hline & Resident & 71 & $4.09 \pm 0.55$ & & \\
\hline & Senior resident & 29 & $4.02 \pm 0.48$ & & \\
\hline & Consultant/Fellow & 4 & $4.29 \pm 0.46$ & & \\
\hline
\end{tabular}

The study also showed that information on annual eye checkup, regular dental check-up and seeking support from family and friends were inadequately communicated to patients. This may imply that the primary care physicians in this study were not providing information on the available resources beyond the primary care clinic that may be beneficial to people living with DM. Previous studies have also shown that physicians in primary care rarely communicate these pieces of information and infrequently refer patients with DM to other specialists even when they are available in their practice setting. ${ }^{17,22}$ The poor collaboration between the physicians and other team members due to the weakness in the utilisation of the available resources in the Nigerian primary health care system for diabetes care may partly explain this finding. ${ }^{6-8}$

Teamwork for DM treatment results in a diffusion of responsibility for care from physicians to nurses, dietitians and patients. ${ }^{23} \mathrm{~A}$ multidisciplinary team approach has been cited to be probably more effective and efficient. ${ }^{6,24}$ Even though primary care physicians in Nigeria may still need to provide DSME to persons with DM, they must always see themselves as part of a communitywide network of support by harnessing resources in the community that may be utilised for the benefits of patients. This includes educating patients on the importance of family support as well as referring persons with DM to other specialists including ophthalmologists and dentists.

There was no association between the quality of physicians' communication of diabetes self-management behaviours and gender based on the summative total mean score. However, in specific domain analysis, male respondents communicated diabetes self-management to patients better than their female counterparts in the problem-solving domain. The literature on the relationship between physicians' performance in each domain in relation to their gender is non-existent. Available studies on the relationship between providers' gender and the quality of diabetes self-management communication point in no specific direction. Similarly to this study, some studies have reported no association ${ }^{17,25,26}$ while another study has shown that female physicians communicate in a more patient-centred way than male physicians. ${ }^{27}$

These conflicting observations may be due to confounders such as patient demographic characteristics and disease severity, which may not be adjusted for in these studies. Kim et al. examined the association between gender of primary care physicians and the quality of diabetes care they provided using the data of the patients who participated in the Translating Research into Action for Diabetes (TRIAD) study. ${ }^{25}$ They reported that patients of female and male physicians received similar quality of care after adjusting for likely confounders. ${ }^{25}$

The other physician-related characteristics, which include age group, length of practice, professional qualification, availability of group counselling programme in respondents' practice setting and formal training in diabetes self-management, were not associated with the quality of physicians' communication of diabetes self-management behaviours. However, it is worthy of mention that among all these physician-related characteristics, formal training in diabetes self-management with a level of significance of $p=0.09$, though not statistically significant, has a certain trend towards significance. Perhaps a larger sample size would have increased the power of the study to detect this. The clinical importance of this finding is that, probably, the quality of physicians' communication may be improved if efforts are geared towards manpower training. A previous study had also reported that doctors' quality of communication of diabetes self-management was significantly better if they had formal training in diabetes selfmanagement. ${ }^{17}$

This work may suggest that the provider-related determinants of quality of physicians' communication of diabetes self-management may be less an issue of demographic characteristics like age group, gender, length of practice, professional qualification of the physicians or functions of the settings in which they practise. The incorporation of disease management programmes that focus on manpower training in diabetes self-management may be more of an issue when it comes to the determinants of quality of diabetes self-management education given by primary care physicians. Further research is needed to examine the effects of disease management programmes on the quality of physicians' communication of diabetes self-management. Aside from the content of DSME provided by physicians, further Nigerian studies are needed to examine the physicians' communication techniques used in providing DSME to people with diabetes.

\section{Conclusion}

The quality of physicians' communication of diabetes self-management is suboptimal in this study. The majority of the 
adequately communicated diabetes self-management behaviours were risk-factor reduction related and disease-centred. Primary care physicians in this study did not adequately communicate diabetes self-management behaviours that may assist patients in seeking help beyond the primary care (annual eye examination and dental check-up) and hospital (support from family members) environments. The determinants of the quality of primary care physicians' self-management information delivered to patients may be associated more with manpower training in diabetes self-management.

This study has implications for both primary care physicians and the healthcare system. The individual primary care physician should strive to adequately communicate self-management behaviours that are not just disease centred but also problemsolving centred. Physicians should inform people with DM about formal and informal supports that are available in their practice setting. The organisation of the health system must encourage an exchange of information to facilitate self-management among people with DM. Periodic training of primary care physicians, who often double as diabetes educators in resourcepoor countries, should be encouraged by government and private healthcare facilities.

\section{Limitations}

This study has several limitations. First, the data on 105 primary care physicians may not be enough to generalise the findings to a larger population of primary care physicians. However, our study is the first study in Nigeria on the content of physicians' communication of diabetes self-management. It has provided important insights into the quality of physicians' communication in the care of DM in Nigeria. In addition, the study can only suggest an association and not causality because it had a cross-sectional design. An interventional study in the future may substantiate the influence of physician characteristics on the quality of DSME provided by primary care physicians. The quality of physicians' communication of diabetes self-management was also based on self-report. The accuracy of the selfdeveloped cut-off points (using the scores corresponding to the 50th percentile in each domain) to distinguish between adequate and inadequate communication of diabetes self-management education cannot be ascertained. Further studies are needed on the relevance of the cut-off point used.

Acknowledgement - The authors appreciate all their colleagues in the Department of Family Medicine, Federal Medical Centre, Abeokuta for their immense contributions during the preparation of the work. Special thanks are offered to the staff of Ace Medicare Clinics, Ota, Ogun State, Nigeria.

Declaration - Ethical clearance was obtained from the Ethical Committee of the Ace Medicare Clinics Ota and the NPGMCN (Faculty of Family Medicine). The authors were responsible for the funding of the research. There is no conflict of interest as the researchers have no financial or personal relationships that may have inappropriately influenced them in writing this paper.

Key messages - Primary care physicians, who often double as diabetes educators in resource-poor countries, should strive to improve their knowledge and skills on the communication of diabetes self-management to people with DM. This may improve self-care practices and glycaemic control among persons with DM.

\section{ORCID}

OS Ojo (D) http://orcid.org/0000-0002-5191-5476

SO Malomo (D) http://orcid.org/0000-0002-8545-5105

AO Egunjobi (D) http://orcid.org/0000-0002-0750-2471

\section{References}

1. International Diabetes Federation. IDF diabetes. 8th ed. Brussels, Belgium: International Diabetes Federation; 2017. [cited 2018 Feb 20]. http://www.diabetesatlas.org.

2. Norris SL, Engelgau MM, Narayan KM. Effectiveness of self-management training in type 2 diabetes: a systematic review of randomized controlled trials. Diabetes Care. 2001;24(3):561-87. doi:10.2337/ diacare.24.3.561

3. Piatt GA, Orchard TJ, Emerson S, et al. Translating the chronic care model into the community: results from a randomized controlled trial of a multifaceted diabetes care intervention. Diabetes Care. 2006;29(4):811-17. doi:10.2337/diacare.29.04.06.dc05-1785

4. American Association of Diabetes Educators. Aade position statement. Diabetes Educ. 2008;34:445-49. doi:10.1177/014572170 8316625

5. U.S. Department of Health and Human Services. National ambulatory medical care survey; 2004.

6. Fasanmade OA, Dagogo-Jack S. Diabetes care in Nigeria. Ann Glob Health. 2015;81(6):821-29. doi:10.1016/j.aogh.2015.12.012

7. Onyekachukwu OO. Promoting diabetes self management education [DSME] through community based care in Nigeria. Int J Trop D Heal. 2016;19(3):1-15. doi:10.9734/IJTDH/2016/28781

8. Iregbu SC, Iregbu FU. A review of self-management of diabetes in Africa. AJDM. 2016;24(2):5-8.

9. Deakin T, McShane CE, Cade JE, et al. Group based training for self-management strategies in people with type 2 diabetes mellitus. Cochrane DB Sys Rev. 2005;(2):CD003417. doi:10.1002/14651858.CD003417.pub2.

10. Keers JC, Groen H, Sluiter WJ, , et al. Cost and benefits of a multidisciplinary intensive diabetes education programme. J Eval Clin Pract. 2005;11(3):293-303. doi:10.1111/j.1365-2753.2005.00536.x

11. Heisler M, Bouknight RR, Hayward RA, , et al. The relative importance of physician communication, participatory decision making, and patient understanding in diabetes self-management. J Gen Intern Med. 2002;17(4):243-52. doi:10.1046/j.1525-1497.2002.10905.x

12. Heisler $M$, Cole I, Weir $D_{1}$, et al. Does physician communication influence older patients' diabetes self-management and glycemic control? Results from the health and Retirement Study (HRS). J Gerontol Med Sci. 2007;62A(12):1435-42. doi:10.1093/gerona/62.12.1435

13. Okokon IB, Ogbonna UK. The consultation in primary care: physician attributes that influence patients' satisfaction in calabar, Nigeria. J Gen Pract. 2013;2(1):135-40. http://doi.org/10.4172/2329-9126.1000135

14. Abiola T, Udofia O, Abdullahi AT. Patient-doctor relationship: the practice orientation of doctors in Kano. Niger J Clin Pract. 2014;17 (2):241-47. doi:10.4103/1119-3077.127567

15. Mulcahy K, Maryniuk M, Peeples M, et al. Diabetes self-management education core outcomes measures. Diabetes Educ. 2003;29(5):76870, 773-84, 787-88 passim. doi:10.1177/014572170302900509

16. Kruse RL, Olsberg JE, Shigaki CL, et al. Communication during patientprovider encounters regarding diabetes self-management. Fam Med. 2013;45(7):475-83.

17. Abdulhadi N, Al-Shafaee MA, Ostenson CG, et al. Quality of interaction between primary health-care providers and patients with type 2 diabetes in Muscat, Oman: an observational study. BMC Fam Pract. 2006;7:72-81. doi:10.1186/1471-2296-7-72

18. Arar NH, Wang CP, Pugh JA. Self-care communication during medical encounters: implications for future electronic medical records. Perspect Heal Inf Manag. 2006;3(3):1-20.

19. Mensing $C$, Eichorst B. Educating the patient with diabetes. In: Holt $R$, Cockram C, Flyvbjerg A, Goldstein B, editors. Textbook of diabetes. 4th ed. Hoboken, New Jersey: Blackwell Publishing; 2010. p. 334-45.

20. Shah BR, Hux JE, Laupacis A, et al. Clinical inertia in response to inadequate glycemic control: do specialists differ from primary care physicians? Diabetes Care. 2005;28(3):600-6. doi:10.2337/diacare.28. 3.600

21. Bodenheimer $\mathrm{T}$, Lorig $\mathrm{K}$, Holman $\mathrm{H}$, et al. Patient self-management of chronic disease in primary care. JAMA. 2002;288(19):2469-75. doi:10. 1001/jama.288.19.2469 
22. Rice DM. Diabetes educators in primary care-a natural fit. USE. 2007;00.2.15-6.

23. Donnelly MB, Anderson RM. The role related attitudes of physicians, nurses, and dieticians in the treatment of diabetes. Med Care. 1990;28(2):175-79. doi:10.1097/00005650-19900200000008

24. Codispoti C, Douglas MR, McCallister T, , et al. The use of a multidisciplinary team care approach to improve glycemic control and quality of life by the prevention of complications among diabetic patients. J Okla State Med Assoc. 2004;97(5):201-4.
25. Kim C, McEwen LN, Gerzoff RB, et al. Is physician gender associated with the quality of diabetes care? Diabetes Care. 2005;28(7):159498. doi:10.2337/diacare.28.7.1594

26. Hyman I, Shakya Y, Jembere N, et al. Provider- and patient-related determinants of diabetes self-management among recent immigrants: Implications for systemic change. Can Fam Physician. 2017;63(2):e13744.

27. Roter DL, Hall JA. Physician gender and patient-centered communication: a critical review of empirical research. Annu Rev Public Heal. 2004;25:497-519. doi:10.1146/annurev.publhealth.25.101802.123134

Received: 28-04-2018 Accepted: 21-07-2018

\section{Appendices}

\section{Appendix I: Informed consent \\ Dear Sir/Madam,}

We hereby seek your consent to participate in this research.

We intend to find out the Quality of Primary Care Physicians' Communication of Diabetes Self-Management During Medical Encounters with Persons with Diabetes Mellitus in a Resource-Poor country with a view to designing a resource guide to diabetes self-management education protocol for primary care physicians and development of patient self-management tools

If you consent, a questionnaire will be administered to you. The procedure will last for about 10 minutes.

Your participation is entirely of your own free will and you can withdraw from the study at any time you like without explanation. You have the right to refuse to answer any question you don't want to answer. Please note that any information collected will remain confidential. Your name will not be attached to any published results.

Kindly indicate your decision by signing in the space below.

Thank you.

Date and signature or thumbprint of participant

Date and signature or thumbprint of witness

Appendix II: Questionnaire

Proforma on Content and Quality of Primary Care Physicians' Communication of Diabetes Self-management to Patients in Nigeria

Good day Sir/Madam,

Thank you for consenting to participate in this study. This research is about looking at the content and quality of primary care physicians' communication of diabetes self-care practices in Nigeria. Truthfully answering the questions will be appreciated. Every piece of information you give will be kept strictly confidential and the interview will not take much of your time. Thank you.

Serial Number

Date

A SOCIODEMOGRAPHIC VARIABLES

1. Age (years):

2. Gender: a) Male b) Female

3. Professional Status:
a) Consultant
b) Senior Resident
c) Resident
d) Medical Officer

4. Highest medical/academic qualification:
a) Fellowship
b) $\mathrm{PhD}$
c) Membership
d) Masters
e) Diploma
f) MBBS

5. Type of practice:
a) Private
b) Public

6. Length of practice:

7. Do you know about diabetes self-care?
a) Yes
b) $\mathrm{No}$ 
8. Have you had a formal training on diabetes self-care or its communication to patients?
a) Yes b) No

9. Do you have a group counselling session by the nurses or other para-medicals in your clinic?

a) Yes b) No

10. In which of the following Nigerian geo-political zones do you practise?
a) South-west
b) South-east c) South-south
d) North-west
e) North-central f) North-east

\section{B PHYSICIANS' DIABETES SELF-MANAGEMENT COMMUNICATION TO PATIENTS}

Kindly indicate how often you communicate the diabetes self-care options stated below

11. Healthy Eating:

\begin{tabular}{|c|c|c|c|c|c|}
\hline How often do you communicate the following to your patients: & Always (5) & Often (4) & Sometimes (3) & Rarely (2) & Never (1) \\
\hline \multicolumn{6}{|l|}{ The foods that are best to eat or avoid } \\
\hline \multicolumn{6}{|l|}{ When and how much to eat } \\
\hline \multicolumn{6}{|l|}{ Developing a practical meal plan } \\
\hline \multicolumn{6}{|l|}{ Preventing high or low blood sugar } \\
\hline Setting goals for healthy eating & & & & & \\
\hline
\end{tabular}

\section{Being Active:}

\begin{tabular}{l}
\hline How often do you communicate the following to your patients: \\
\hline Exercise is important in managing their condition
\end{tabular}

\section{Monitoring:}

\begin{tabular}{|c|c|c|c|c|c|}
\hline How often do you communicate the following to your patients: & Always (5) & Often (4) & Sometimes (3) & Rarely (2) & Never (1) \\
\hline \multicolumn{6}{|l|}{ The way to use a blood sugar (glucose) meter } \\
\hline \multicolumn{6}{|l|}{ When to check your blood sugar and what the numbers mean } \\
\hline \multicolumn{6}{|l|}{ What to do when your numbers are out of your target range } \\
\hline \multicolumn{6}{|l|}{ How to record blood sugar results } \\
\hline Regular blood pressure, cholesterol and weight check & & & & & \\
\hline
\end{tabular}

\section{Taking Medications:}

\begin{tabular}{|c|c|c|c|c|c|}
\hline How often do you communicate the following to your patients: & Always (5) & Often (4) & Sometimes (3) & Rarely (2) & Never (1) \\
\hline \multicolumn{6}{|l|}{ Knowing their medications } \\
\hline \multicolumn{6}{|l|}{ The reason for using the medications } \\
\hline \multicolumn{6}{|l|}{ How the medications are used and how to fit them into their schedule } \\
\hline \multicolumn{6}{|l|}{ Knowing some of the side effects of the medications } \\
\hline \multicolumn{6}{|l|}{ Knowing what to do in the event of side effects } \\
\hline Knowing what to do if the medications are forgotten & & & & & \\
\hline
\end{tabular}




\section{Problem Solving:}

\begin{tabular}{|c|c|c|c|c|c|}
\hline How often do you communicate the following to your patients: & Always (5) & Often (4) & Sometimes (3) & Rarely (2) & Never (1) \\
\hline $\begin{array}{l}\text { Problem may arise even when they follow self-management of diabetes } \\
\text { Don't beat yourself up when problems arise }\end{array}$ & & & & & \\
\hline Think about what was different when there are problems & & & & & \\
\hline Learning from the problem when it happens & & & & & \\
\hline Discuss possible solutions with their doctors & & & & & \\
\hline Try the new solutions and then evaluate whether they are working for you & & & & & \\
\hline
\end{tabular}

\section{Reducing Risks:}

\begin{tabular}{|c|c|c|c|c|c|}
\hline How often do you communicate the following to your patients: & Always (5) & Often (4) & Sometimes (3) & Rarely (2) & Never (1) \\
\hline \multicolumn{6}{|l|}{ Don't smoke } \\
\hline \multicolumn{6}{|l|}{ See your doctor regularly } \\
\hline \multicolumn{6}{|l|}{ Visit the eye doctor at least once a year } \\
\hline \multicolumn{6}{|l|}{ The need for regular dental check-up } \\
\hline \multicolumn{6}{|l|}{ Take care of your feet } \\
\hline Report any abnormal feelings to the doctor & & & & & \\
\hline
\end{tabular}

\section{Healthy coping:}

\begin{tabular}{|c|c|c|c|c|c|}
\hline How often do you communicate the following to your patients: & Always (5) & Often (4) & Sometimes (3) & Rarely (2) & Never (1) \\
\hline \multicolumn{6}{|l|}{ Seeking support from family and friends } \\
\hline \multicolumn{6}{|l|}{ Being active } \\
\hline \multicolumn{6}{|l|}{ Thinking positive } \\
\hline Being good to yourself & & & & & \\
\hline
\end{tabular}

